\title{
O CONVIVIO COM A DOR: UM ENFOQUE EXISTENCIAL ${ }^{1}$
}

\author{
LIVING WITH PAIN: AN EXISTENTIAL FOCUS
}

\section{EL CONVIVIO CON EL DOLOR: UN ENFOQUE EXISTENCIAL}

\author{
Luciane Maximiliano Sanches* \\ Magali Roseira Boemer**
}

Sanches LM, Boemer MR. O convivio com a dor: um enfoque existencial. Rev Esc Enferm USP 2002; 36(4): 386-93.

\section{RESUMO}

No cotidiano de um hospital, em meu sendo-enfermeira, cuidando de pacientes com dor, essa mostrou-se a mim para além de uma esfera biológica, inserindo-se em uma dimensão existencial. Deste conviver, algo me inquietou e senti necessidade de compreender essas pessoas em situação de dor passando a questionar: como a pessoa compreende a sua dor? Qual o significado de vivenciar situações dolorosas em sua cronicidade? . Na tentativa de encontrar um caminho para tal compreensão, busquei por algumas idéias da fenomenologia. Foram realizadas entrevistas individuais, fundamentada na questão norteadora: "Como vem sendo para o (a) senhor (a) o convivio com a dor? Conte-me sobre isto". Após análise, pude compreender que a dor é uma forma de estreitamento do horizonte de possibilidades, de transformações na existência. Não é somente o corpo físico que se encontra doente, mas a vida em suas várias dimensões ficam afetadas, fundamentalmente no que se refere ao mundo familiar, do trabalho e da auto-relação.

PALAVRAS-CHAVE: Dor. Fenomenologia.

\section{ABSTRACT}

In the routine of a hospital, during my nursing practice of providing care to patients with pain, it was shown to me as reaching beyond a biological sphere included in an existential dimension. Something in this experience disturbed me and I felt the need to understand these people suffering from pain, asking how they understand their pain and what is the meaning of experiencing painful chronic situations. In the attempt to find a way to obtain such understanding, I searched for some ideas stemming from phenomenology. Then, I interviewed the subjects individually based on the central question: "How is your experience with pain? Tell me about this". After the analysis, I was able to understand that pain is a way to narrow the horizon of possibilities and transformations in existence. It is not only the physical body that is ill, but also life is affected in its various dimensions, fundamentally with regard to the family, work and self-relation world.

KEYWORDS: Pain. Phenomenology.

\section{RE SUMEN}

En el cotidiano de un hospital, la actuación de la enfermera cuidando de pacientes con dolor, demuestra más que una esfera biológica, incluyendose en una dimensión existencial. A partir de este convivir, algo despertó a la autora que sentió la necesidad de comprender las personas en situación de dolor, cuestionando: como la persona comprende su dolor? Cuál es el significado de vivir situaciones dolorosas en su cronicidad? En la tentativa de encontrar un camino para esta comprensión, la autora buscó por algunas ideas de la fenomenologia. Fueron realizadas entrevistas individuales, fundamentadas en la cuestión norteadora: "Como es y ha sido su convivio con el dolor? Hable sobre esto. Después del análisis, la autora comprendió que el dolor es una forma de estrechamiento del horizonte de posibilidades, de transformaciones en la existencia. No es solamente el cuerpo fisico que se encuentra enfermo, pero la vida en sus várias dimensiones también está afectada, fundamentalmente en lo que se refiere al mundo familiar, del trabajo y de la auto-relación.

PALABRAS -CLAVE: Dolor. Fenomenologia.

\footnotetext{
${ }^{1}$ Resumo da Dissertação de Mestrado (mesmo título) apresentada ao Departamento de Enfermagem Geral e Especializada da * Escola de Enfermagem de Ribeirão Preto da Universidade de São Paulo (EERP/USP) em 04 de junho de 2002.

*Enfermeira. Mestranda em Enfermagem Fundamental pela EERP/USP, 2002. Email:ludoug@ig.com.br

**ientadora. Professora Associada Aposentada da Escola de Enfermagem de Ribeirão Preto/USP.Vínculo atual com Pós-

Graduação e CNPq. Email:boemer@eerp.usp.br
} 


\section{INTRODUÇÃO}

Durante parte de minha graduação em enfermagem fui Bolsista de Iniciação Científica junto a um Projeto Integrado cujo tema central é a morte e o morrer. Realizei, então, muitas leituras com a intenção de desenvolver minha sensibilidade em relação à essa temática, o que inclui estudar o morrer, a perda, a dor, a dignidade humana, entre outras facetas do tema.

Realizei também alguns estágios relacionados à dor. Entre eles, no Ambulatório de Dor do Hospital das Clínicas da Faculdade de Medicina de Ribeirão Preto-USP (HCFMRP-USP), atualmente denominado "Clínica para o Tratamento da Dor". Naquele momento, observei que médicos e enfermeiros buscavam, fundamentalmente, amenizar a dor fisica dos pacientes, enfocando-a como causa única de sofrimento, numa postura advinda de uma formação profissional relacionada ao modelo biomédico vigente no contexto hospitalar, que restringe a visão do adoecer. Esses estágios possibilitaram-me, ainda na condição de aluna de enfermagem, uma primeira aproximação à essa relevante questão.

Ao graduar-me, passei a habitar o mundo de um setor de Recuperação Pós Anestésico de um Hospital Universitário, onde o cuidado que prestava voltava-se, basicamente, para assistência à pessoa no período pós-operatório imediato. Além desses cuidados, prestava assistência também a pacientes com dor crônica, quando submetidos à bloqueios ganglionares com anestésicos. Algumas vezes esses pacientes ficavam na Seção de Recuperação devido aos efeitos colaterais dos bloqueios. Podia, então, perceber a impaciência ou talvez despreparo por parte dos profissionais de saúde no que se refere à dor, pois esse paciente é considerado como "queixoso", "impaciente".

De acordo com a Associação Internacional para Estudos da Dor, podemos defini-la como "uma experiência sensorial e emocional desagradável, associada a lesão real ou potencial dos tecidos, ou descrita em termos de tais danos. Cada indivíduo aprende a utilizar este termo através de suas experiências anteriores..." É uma experiência subjetiva e pessoal(1) A dor crônica é descrita como uma dor que dura meses, anos ou a vida toda, podendo haver ocorrências intermitentes que se caracterizam por períodos de dor, intercalados com outros dela isentos ${ }^{(2)}$.

A sua quantificação e qualificação são fundamentalmente definidas e baseadas no relato verbal e nas atitudes dos doentes. A qualidade da dor pode ser avaliada através de escalas numéricas, de analogia visual, pela descrição voluntária da sensação, por analogia com outras sensações ou por inventários ${ }^{(3-4)}$.

Uma incursão pela literatura mostrou-me que, nos últimos anos, tem havido maior preocupação em estudar a dor e suas implicações para as pessoas.
Surgiram, também, as Clínicas de Dor, as quais procuram abordar, simultaneamente, os seus aspectos físicos, emocionais, cognitivos, comportamentais, vocacionais e sociais.

Algumas inquietações se impuseram então, tais como: Qual a percepção deste indivíduo em relação à sua dor? O que significa uma existência na qual os analgésicos estão presentes cotidianamente? Qual o significado de conviver com uma dor em sua cronicidade?

Essas inquietações levam-me a optar por um estudo de natureza fenomenológica, pois esta constitui-se em uma das modalidades da pesquisa qualitativa que lida com valores, crenças e significados atribuidos pelas próprias pessoas. Segundo este pensar, a pesquisa se norteou sob a interrogação: $o$ que é isto, o conviver-com-a-dor?

\section{FUNDAMENTAÇÃo TEÓRICO- METODOLÓGICA}

A Fenomenologia, proposta por Husserl, no início do século XX, na Alemanha, é definida como ciência descritiva, rigorosa, concreta, que mostra e explicita o ser nele mesmo, que se preocupa com a essência do vivido(5).

O lema de Husserl "volta às coisas mesmas" é uma tentativa de aproximação às coisas sem preconceitos ou pressupostos interpretativos (a priori). Assim, ele define a fenomenologia como "ciência dos fenômenos", sendo fenômeno compreendido como o que é imediatamente dado em si mesmo à consciência, ou seja, aquilo que surge para uma consciência, o que se manifesta para essa consciência como resultado de uma interrogação.

Enquanto modalidade de pesquisa qualitativa, a fenomenologia busca a compreensão do fenômeno interrogado, não se preocupando com explicações e generalizações. O pesquisador não parte de um problema específico nos moldes das ciências empíricas, mas conduz sua pesquisa a partir de uma interrogação acerca de um fenômeno, o qual precisa ser situado, ou seja, estar sendo vivenciado pelo sujeito.

No desvelar do fenômeno interrogado, o pesquisador não parte de teorias ou explicações a priori, mas do mundo-vida dos sujeitos que vivenciam o fenômeno em questão. O que se busca na pesquisa fenomenológica são os significados que os sujeitos atribuem à sua experiência vivida, significados esses que se revelam a partir das descrições desses sujeitos(6).

\section{O LOCAL E OS HUMANOS DO ESTUDO}

O trabalho foi realizado na Clínica para o Tratamento da Dor do Hospital das Clínicas da 
Faculdade de Medicina de Ribeirão Preto-Universidade de São Paulo (HCFMRP-USP). Os sujeitos foram os pacientes portadores de dor crônica não neoplásica (fibromialgia, dor neuropática, lombalgia, entre outras), submetidos à bloqueios anestésicos, independente de sexo, raça, religião e nivel sócio-econômico-cultural. Foram escolhidos aqueles com dor crônica não-neoplásica por terem, na dor, o fator limitante de suas atividades diárias, o que inclui sono, movimentação e deambulação, atividade sexual, trabalho... Não foram incluídas pessoas com dor neoplásica, por acreditar não ser somente este o fator limitante de suas atividades, considerando que essa pessoa já vem sofrendo alterações biopsicossociais no processo de sua doença .

Após consentimento deste Setor e aprovação do Comitê de Ética em Pesquisa do hospital (ANEXO 1), passei a habitar o mundo dessa clínica com o intuito de melhor conhecer o seu cotidiano e aproximar-me das pessoas em situação de dor. Ao abordar o paciente, apresentei-me como enfermeira-pesquisadora que estava ali, naquele momento, com a proposta de aproximar-se dele para compreendê-lo em sua experiência de dor. Antes de recorrer às entrevitas, me dispus a estar com estes pacientes, conversando, ouvindo, realizando alguns procedimentos de enfermagem como puncionar acesso venoso para infusão de medicamentos. Tudo isso nos aproximou, gerando um relacionamento de confiança, de empatia. Foi fundamental este envolvimento, pois possibilitou maior abertura em suas falas no momento da entrevista. Informei-os, individualmente, quanto ao objetivo da pesquisa e, após obter por escrito o termo de consentimento livre e esclarecido para participar do estudo, dei início às entrevistas individuais. Esse "tempo vivido" com cada um, ao lado da sua fala específica à questão, é que possibilitou a análise.

Os encontros aconteceram no periodo de janeiro a agosto de 2001, as terças e quartas-feiras de manhã, horário em que os pacientes se encontravam no hospital. A entrevista norteou-se na questão: Como vem sendo para - (a) senhor(a) o convivio com esta dor? Conte-me sobre isto.

Conforme descrito no Termo de Consentimento Livre e Esclarecido (Anexo I), foi respeitada a vontade de cada participante quanto ao uso do gravador no momento da entrevista. Em relação ao número de pessoas a serem entrevistadas foi obedecido o critério da repetitividade, que é o adotado quando se trabalha com discursos no referencial teórico-metodológico da fenomenologia, buscando pelas suas convergências e divergências que elucidam o interrogar do pesquisador. Dezesseis depoimentos foram obtidos e analisados.

\section{CONSTRUÇÃO DOS RESULTADOS}

\section{Considerações Preliminares}

Para proceder à análise dos depoimentos de pessoas que convivem com a dor foi necessário ler seus depoimentos norteados pela questão proposta até ver com clareza, tomando cuidado para não exercer juízo sobre as falas. Nesse processo procurei perscrutá-lo cuidadosamente, procurando, nas palavras utilizadas pelos sujeitos, encontrar o sentido que melhor descrevesse o seu dizer, que iluminasse sua fala, ou seja, atentando para as convergências, divergências e peculiaridades entre elas. Esse trabalho permitiu a elaboração de seis categorias temáticas de análise, abrindo possibilidades de revelar a percepção do seu ser-no-mundo convivendo com a dor. Para análise dessas categorias apropriei-me de algumas idéias de Heidegger, por entender que o pensamento deste filósofo permite novos horizontes de compreensão e se coaduna com a natureza mesma de minhas inquietações.

\section{Algumas idéias de Heidegger}

A fenomenologia, considerada por Heidegger como uma possibilidade, mostra um visão diferenciada daquela das ciências naturais e experimentais e proporciona desvelar facetas da existência humana.

Segundo Heidegger, quando se pretende estudar o homem torna-se imprescindivel questionar o que significa ser homem. Em sua obra "Ser e Tempo"), faz uma tentativa de compreender a existência do ser humano ontologicamente a partir da explicação do ente, o seraí (Dasein). Por ente, devemos entender "tudo aquilo que de nós falamos, tudo em que pensamos, tudo em relação a que nos comportamos, mas também o que nós próprios somos e a maneira como nós somos."

"Ser-aí" é a denominação que Heidegger(7) dá ao ente humano. Ele é um ente que não se limita a colocarse diante de outros entes, pois tem também uma relação consigo mesmo, procura uma compreensão de si. Portanto, o ser-aí é definido como um ente que, em cada caso sou eu mesmo, o que significa que cada ser humano tem suas características próprias embora todos guardem possibilidades semelhantes. Este ente que é cada um de nós, tem, entre outras possibilidades, a de ser, a de questionar-se.

De acordo com Heidegger, o que caracteriza o "Dasein" é o ser-no-mundo, estrutura que é captada pelo homem no seu próprio existir. A essência do homem está em seu "ser relativamente a" alguma coisa ou alguém. O "ser-no-mundo" vive simultaneamente o mundo dos objetos que o rodeiam, o mundo natural (Unwelt), o mundo das relações com os seus semelhantes (Mitwelt) e o seu mundo pessoal, das suas relações consigo mesmo (Eingewelt)(8).

Passo, então, ao relato e descrição das categorias, com vistas à compreensão do fenômeno conviver com a dor aos olhos de quem a vivencia.

A dor, aos olhos de quem a experiencia, se mostra como:

ALGO INCAPACITANTE PARA VIVENCIAR O COTIDIANO 
Pouco a pouco a dor passa a fazer parte da vida da pessoa. Com o tempo ela se torna mais intensa e passa a incomodar durante o sono, impondo limitações em suas atividades cotidianas como, por exemplo, pentear o cabelo, dormir. Algumas falas permitem essa apreensão:

Até pentear o cabelo... tem dia que a gente não consegue nem fazer isso. A gente tem que cortar mais curto pra ficar mais fácil. (Depoimento 1)****

A dor vem atrapalhando a vida...Porque não consigo dormir direito por causa da dor. No dia seguinte a gente já levanta indisposta, levanta nervosa, atrapalha as atividades. (Depoimento 2)

O medo de sentir dor é responsável, na maior parte dos casos, pela conduta de fugir de atividades ou situações a ela relacionadas, o que resulta na manutenção da incapacidade( ${ }^{(9)}$.

Só que quando eu to... que eu sinto que eu to meio incapacitada para alguma coisa, que eu não dou conta mais de fazer isto, ai, eu fico bem aborrecida... mas ai, também...eu respiro fundo e falo:-Ah! Não tem jeito mesmo! Então vou fazer o que dá pra fazer, né...e, assim, eu venho tocando minha vida... (Depoimento 6)

Além das dificuldades rotineiras do cotidiano traz, muitas vezes, a impossibilidade de desenvolvimento das atividades profissionais. O trabalho constitui-se em uma questão fundamental pois, além de ser o meio de garantir a vida material, constitui-se na essência do ser humano. A mudança na capacidade para o trabalho não é facilmente aceita, conforme pode ser percebido no depoimento:

E a parte psicológica que mexe, é que eu trabalho na cozinha...é industrial...é cozinha de uma lanchonete, e eu sei que já contrataram outra pessoa...porque eu não tenho serventia nenhuma quando eu voltar a trabalhar com o braço desse jeito (Depoimento 5)

A necessidade do afastamento do trabalho foi vivenciada pelos entrevistados considerando que a limitação causada pela sintomatologia apresentada interfere na produtividade do trabalho.

...eu não sou feliz por ser afastada...pelo contrário... eu me sinto mal, ter que ir lá receber esse dinheiro.. Ter que ir lá receber o dinheiro, pra mim é mal...quando eu entro na fila e vejo aquele bando de velho! (Depoimento 6)
Olha...não é fácil...porque eu tenho vinte $e$ sete anos e eu já tô aposentada. (Depoimento13)

Mesmo sabendo que existem limitações, muitos estão dispostos a tentar produzir como antes, pois a manutenção do trabalho contribui para manter a pessoa ativa, participante, minimizando o desconforto e melhorando a auto-estima. Suas falas revelam essa faceta:

Eu vou por teimosia, eu vou porque preciso e eu tenho medo mesmo de parar e entrevar de vez.,. porque tem hora que eu sinto...Ah! Meu Deus! Eu levanto da cama e a impressão que eu tenho é que não vou conseguir, sabe? (Depoimento 6)

Para outros, o retorno ao trabalho significa fonte de maior sofrimento, principalmente quando percebem que estão limitados em suas capacidades fisicas e não conseguem produzir como antes. Sentem-se humilhados:

...Nossa! É uma humilhação...você fica um pouco triste, porque na reabilitação, quando você vai fazer na firma, você pensa:- Nossa! Entrei boa... você vai, entra lá...como se diz...quando você ta boa, eles precisa de você...quando você precisa deles, eles não quer saber de você...É muito humilhante, porque as pessoas olham pra você e falam assim: Nossa! Lá vem a fila do INSS... (Depoimento16)

Apesar dos indícios de que a dor prejudica a vida profissional dos brasileiros e os leva até mudar de emprego, seu impacto na economia do país é ignorado. O tema é subestimado pelo governo e pelo empresariado. Desde 1995, quando pesquisa da USP mostrou que 95\% dos pacientes de hospitais brasileiros tinham a carreira afetada pela dor, não existem estudos aprofundados. Não há dados abrangentes sobre fatores como perda de produtividade, faltas ao trabalho e despesas geradas pela dor 19

Nos Estados Unidos, ela provoca perdas de US\$ 100 bilhões ao ano em função de queda de produtividade e faltas ao trabalho(10),

Alguns relataram também alterações nas suas atividades de lazer como: leitura, participar de festas, sair para pescar, o que acabou restringindo-lhes a vida social, como acompanhamos no depoimento a seguir:

...eu gosto muito de ler. Mas até a leitura me irrita, porque cansa o braço esquerdo, pra segurar o livro...aí, você vai usar o braço que está doente, que no meu caso é o direito, ai, começa a sentir dor. A partir do momento que você começa a sentir dor, você se desinteressa pela leitura e ainda perde algumas páginas, volta algumas paginas que já tinha lido...é aquela brincadeirinha de vai e vem. (Depoimento 5) 
O desejo de produzir e a impossibilidade de executar as suas atividades da mesma forma que antes criam conflitos e constrangimento para eles. Nesse sentido, ir à compreensão do ser-pessoa-com-dor significa interpretá-la enquanto ser-no-mundo que se projeta com possibilidades e facticidades. Como podemos perceber, a existência dessas pessoas é permeada por angústias, medo e sentimento de incapacidade.

A sua existência fica marcada por essa facticidade, transformada pelas ações biológicas e psicossociais causadas pela dor e pelas alterações na auto-estima.

\section{A dor aparece, ainda como:}

\section{ALGO QUE AFETA O SEU SER-NO- MUNDO-COM-OS-OUTROS}

A dor, em sua cotidianidade, provoca mudanças que afetam a pessoa e interferem no seu convivio familiar. O seu ser-no-mundo com sua família é afetado, modificando as relações pais/filhos, marido/ mulher. As falas expressam a percepção que têm dessas modificações:

A dor me deixou impotente, me trouxe a separação do marido, a perda de afeto dos filhos... (Depoimento 5)

...tem que dar atenção pro marido, pro filho...e tem dia que a gente não tem vontade. O filho... A noite quer atenção, quer brincar e a gente tem que ter ânimo pra isso... mesmo com dor.

\section{(Depoimento 9)}

Nesse cotidiano permeado pelo sofrimento, a pessoa se distancia cada vez mais dos outros, dificultando trabalhar essas situações, não conseguindo compartilhar os seus sentimentos e suas angústias com o outro. Sente a dor como processo de separação:

Quando ele me procurava, pouquissimas vezes eu falei: -Não! Tô com muita dor. A maioria das vezes eu falei: -Não...tem que ser, não adianta... não adianta...porque até quando vou falar que eu tô com dor meu Deus?. No começo, eu recusava muito, mas depois eu comecei ver e falei: -Gente! Não é assim, não adianta...eu vou perder o marido! Vou mesmo! Porque até quando eu vou recusar? Você tem que fazer as coisa sem tá com vontade, com dor, sem dor. (Depoimento 6)

A sensação dolorosa acaba se interpondo no modo de ser dá pessoa na família e em todas as suas relações, com maior ou menor intensidade. A existência do sercom-dor é uma existência conflitiva. Sua situação de doente transcende a de sua posição no contexto familiar. ...não ta sendo fácil a convivência. Nem a convivência dentro de casa não ta fácil, porque... a gente com dor não pode fazer nada....e eles não querem que eu comente que eu to com dor, nem que eu reclame...e é difícil...é difícil. (Depoimento 14)

As atividades do cotidiano e problemas corriqueiros transformam-se numa crise. A pessoa, diante de um fato "banal", tende, às vezes a manifestar-se por meio de uma resposta agressiva, interferindo no relacionamento:

\section{E meus filhos, agora, até que estão tentando me entender. já aconteceu de eu jogar copo na parede... de eu pegar o prato que eu estava comendo e jogar lá no muro...porque começava a comer e de repente a dor era muita e ai perde o controle...comecei a perder o controle. (Depoimento 2)}

Há relatos de alguns depoentes que revelam sentir necessidade de afastamento, de isolamento:

Tem dia que eu já levanto com aquele desânimo, sabe? Vontade de ficar sozinha...de chorar, sair correndo, sei lá, sabe? Ficar no mato, isolada. (Depoimento 10)

Estamos sempre em busca daquilo que somos, que é ser-com-outro. Nenhuma pessoa existe se não for com algo ou alguém. Isto é existencial do Ser. Mesmo que o ser-aí não esteja voltado para os outros, ou que consiga um modo de viver sem eles ou se isole, ainda assim ele está no modo do ser-com, embora numa relação deficiente de ser-com. Todo ser é- sempre sercom. Mesmo na solidão e isolamento, o mundo é sempre compartilhado, o viver é sempre com-vivência (7)

As pessoas aprendem e são incentivadas desde a infância a buscar a sua autonomia e independência. Quando ocorre uma situação que restringe ou impede suas ações, como liberdade de movimento, isso as colocando numa situação de dependência para a execução dessas atividades. Experimentam, então, emoções diversas, como podemos ver em algumas falas:

Doïia... a ponto de não poder nem levantar o braço para tirar a roupa, minha irmã que tirava, vestia, tudo... (Depoimento 2)

Hoje eu dependo, às vezes, de duas ou três pessoas pra me ajudar pra mim tomar banho... eu ia lavar o pé e não conseguia... (Depoimento 14)

Em alguns depoimentos emerge o apoio da família no sentido de ajudá-los a enfrentar problemas, como a incapacidade e auto-estima. 
...eu_graças à Deus, em casa, até que tenho um apoio muito bom. $\hat{E}$, acho que é o importante também, porque.... ninguém vem bater na sua porta perguntar se você tá precisando de ajuda, né...Pra criticar tem bastante, né...ma pra te ajudar tem pouco. Acho que o importante é isso...é ter apoio em casa. (Depoimento 13)

A familia é parte fundamental na construção da saúde de seus membros, pois tem como função básica o apoio, segurança e proteção. Agem numa forma de solicitude, às vezes fazendo tudo por eles, outras vezes possiblitando o crescimento, amadurecimento e a seguir seus próprios caminhos.

Outro dado apreendido nas falas é que a dor é:

\section{ALGO QUE AS PESSOAS AO REDOR NÃO COMPREENDEM}

A dor crônica, muitas vezes, é mal compreendida pelos profissionais de saúde e doentes, pois nem sempre há identificação objetiva dos fatores que a provocam. Muitos tiveram que conviver com a desconfiança de colegas e familiares que não compreenderam as suas dificuldades. A incompreensão vivenciada evidenciase em alguns depoimentos:

A gente leva o relatório lá no médico do INPS, ele olha assim, á ...e joga... pra eles, eu tô boa, porque não dá nada nos exame. . (Depoimento 3)

...tem médico que não acredita na dor...ele acredita se eu chegar sangrando, sabe? Se eu chegar toda estourada, ai, vem aquele monte de médico, aquele monte de enfermeira, mas se a dor é interna, hum! (Depoimento 5)

A dor crônica é uma doença com pouca visibilidade e a aparência de seus portadores é a de pessoas normais, sadias. Essa característica da doença acarreta a necessidade de provar para os demais o que eles sentem, para afirmarem que não é "psicológico" o quadro apresentado. Mesmo para alguns profissionais de saúde parece que existe a necessidade da comprovação, a partir de uma evidência, que torne a doença visível. Talvez essa atitude esteja relacionada ao fato de que as pessoas acreditam no que é visivel e, assim, muitas vezes, não confiam no relato do paciente.

...quem olha não vê o problema, não sabe...não sente a dor que você sente. Então, você fica como que meio aproveitadora na história, né...Ah! E corpo mole! - Mas não é.... (Depoimento 13)

Então, é uma prova de fogo, você tem que provar o que você tem. (Depoimento 16)
A falta de compreensão e credibilidade das dificuldades vivenciadas ocorre também com pessoas da família.

Às vezes, falo assim pra minha mãe: - Ah! Tá doendo...Ela fala: - O, menina que reclama! Então, as pessoas não acreditam muito. Acha que é frescura da gente...mas não é não. (Depoimento 15)

A pessoa com dor, enquanto ser-no-mundo, está lançada no mundo. Tendo que se constituir a partir do cuidado do outro, sofre quando se depara com a postura de alguns profissionais que não a respeitam enquanto tal, que não acreditam na sua dor, o que inviabiliza um cuidado integral, humanizado .

A relação com o ser com dor requer o envolvimento da equipe multiprofissional onde cada um possa se dispor, com seus recursos técnicocientífico-humanísticos, a envolver-se com a pessoa doente, em solicitude.

\section{ALGO CUJO ALÍVIO REQUER PACIÊNCIA}

Pessoas com dor crônica são atendidas, muitas vezes, por períodos prolongados, o que acaba gerando momentos de desânimo como podemos ver no depoimento:

Aqui na Clinica de Dor, já vai pra três anos que eu tô vindo, né. O máximo de espaço que eu fiquei sem vir foi um mês, né Você vê... toda semana, toda semana, toda semana, toda semana... a mesma coisa. . (Depoimento 13)

Muitos residem em outras cidades da região. Se deslocam de suas casas muito cedo e permanecem por periodos de 10 a 12 horas no hospital, aguardando transporte, o que também torna todo o processo desgastante:

Pra mim que vem de outra cidade, a gente levanta quatro horas da manhã, vem pra tomar um remédio pra dor...chega aqui, você sofre! As pessoas brinca assim: Você vai pra lá tirar a dor e sai com dor? (Depoimento 6)

Percebemos que o homem vive em um mundo de continuas mudanças, construindo sua história na qual ele é, ao mesmo tempo, o agente e o espectador deste mundo, o que envolve escolhas. A pessoa com dor se vê num dilema: ou aceita o tratamento que lhe é oferecido, apesar das dificuldades, ou permanece com dor. Para amenizar este sofrimento é necessaria uma abordagem multidisciplinar, envolvendo o tratamento físico, social e psicológico, de forma que o plano de atendimento atenda às necessidades de cada paciente..

\section{ALGO QUE REQUER SABER CONVIVER}


Compactuar com a concepção do doente de que só poderá viver quando a dor "for embora", pode ser improdutivo, considerando que, muitas vezes, a dor não "irá embora". Talvez se possa auxiliá-los a compreender que a dor crônica, de certo modo, se parece com outras "dores da vida", que nem sempre vão embora, que nem sempre são extinguíveis. Talvez seja possivel aprender a contornar alguns caminhos e situações, valorizar alguns aspectos, minimizar outros e redimensionar a trajetória, considerando a realidade de cada um.

...mesmo com os próprios pacientes que vem... você vai conversando $e$, mesmo não querendo, o assunto é esse...Aqui está todo mundo com dor...então, com isso a gente vai aprendendo muito e a gente vai se sentindo mais forte para enfrentar a dor. (Depoimento 2)

Eu acho que agora eu já aprendi a conviver com a dor. Busquei forças na religião e em outras coisas e isso me ajudou.(Depoimento 9)

Quando a dor persiste por dias e semanas, a pessoa adapta-se a ela, mesmo sem o perceber. Tornase suportável ou intermitente, ainda que não mude em intensidade e passa a ser uma faceta da existência do paciente e de sua familia:

Antes eu só me lamentava, chorava... então, busquei mudar isso dentro de mim. Achei que lendo, buscando, tendo fé, eu mudaria minha situação. (Depoimento 9)

..junta aquela dor.. junta aquela mágoa. Acho que eu não posso guardar pra mim, tenho que conversar. (Depoimento 10)

Compreender a pessoa com dor em seu mundo é um colocar-se numa maneira de ajudá-lo a conviver com suas perspectivas. É compreendê-lo em seu horizonte de possibilidades no que tange ao seu conviver com sua dor. Ela depara-se com sua facticidade de ser-pessoa-comdor e este é o modo como ela pode estar frente a frente consigo mesma e compreender esta verdade que faz parte de sua existência.

\section{A DOR SE MOSTRA COMO ALGO QUE AFETA A DIMENSÃO EXISTENCIAL}

Pude apreender que as mudanças ocasionadas pela dor não se ativeram aos aspectos físicos, mas causam também abalos na vida mesma das pessoas. $E$ evidente a dimensão existencial nos depoimentos:

Não é só a doença... mas desestrutura a parte emocional, fisica, espiritual.. (Depoimento 9)

Somente quem passa pela triagem toda que a dor passa...é que vai saber explicar $e$ entender que é três dor ao mesmo tempo: é a dor da humilhação, é a dor do

\section{descrédito dos médicos e a dor física} também. (Depoimento 5)

Penso que a dificuldade de aceitação das mudanças advindas da dor torna-se mais penosa porque, geralmente, as pessoas acometidas estão numa fase de vida na qual estão lutando para conseguir sua independência ou já a conquistaram:

Ele (refere ao marido) falou pra mim assim: Pode deixar que eu lavo, eu não sou aleijado, eu tenho os dois braços... (choro). Isso magoou muito, porque eu também não sou aleijada (Depoimento 6)

As emoções frequentemente interligadas à dor são a ansiedade, o medo, a depressão, a raiva e a hostilidade. As duas primeiras referem-se, principalmente, às situações agudas e, as demais, aos quadros crônicos". Depressão é o aspecto emocional mais frequente e o mais estudado na dor crônica e há evidências de que se relaciona à sua intensidade(12). A depressão aparece em algumas falas:

Quando tive o bebê, entrei em depressão, porque eu tinha dificuldade em cuidar dele...não conseguia segurar ele no colo por muito tempo. Tive que desmamar antes do tempo, porque não agüentava segurar ele. Isso mexeu muito comigo... porque acho que toda mulher quer ter um filho um dia,e quando eu tive, nem pude curtir...segurar em meus braços. (Depoimento 9)

...o tipo de depressão que dá não é assim aquela depressão de chorar, de se desesperar, eu simplesmente fico apática, não tenho vontade de sair (Depoimento 5)

O homem não é algo pronto, e sim um conjunto de possibilidades que vai se modificando no decorrer de sua existência. Ele é livre para escolher entre as muitas possibilidades, mas sua escolha é vivenciada com inquietação, pois a materialidade de seu existir não lhe permite escolher tudo. Cada escolha implica na renúncia de muitas possibilidades. Existir é estar em constante processo, indo sempre adiante, caminhando para um futuro que se abre diante de nós, com possibilidades imprevisiveis e incontroláveis ${ }^{(13)}$ Apesar da condição de doença, o serno-mundo continua existindo no mundo e para o mundo.

\section{PERSPECTIVAS DE COMPREENSÃO}

A dor é urna forma de limitação de possibilidades ou de transformações da existência. Ela significa um agravo à existência, porque não é somente o corpo físico que se encontra doente, mas a vida em suas várias dimensões, corno a sua relação consigo mesma, família, trabalho, lazer. 
Neste sentido, percebendo que o convivio com a dor envolve questões existencias e percebendo que a fenomenologia, enquanto movimento filosófico, permite a "volta às coisas mesmas", ousei trabalhar o convivercom-a-dor nesta direção, buscando a compreensão da pessoa que vivencia a dor, ou seja, permitir um movimento no qual sua trajetória de vida fosse efetivamente considerada. O movimento fenomenológico, na perspectiva heideggeriana, possibilita singularizar e humanizar o cuidado e, certamente, abre possibilidades para a melhora da sua qualidade de vida.

A concepção biologista na prática da saúde ainda hoje tem seu caráter predominante. Infelizmente, tal concepção reduz o ser humano ao aspécto biológico, ôntico, impossibilitando o doente de revelar-se como ser-no-mundo-com-os-outros, com suas características ontológicas. E possível e necessário que os profissionais de saúde auxiliem estas pessoas nas diversas facetas de sua existência de ser-pessoa-comdor, dispondo-se a interagir com elas numa forma de ser-com, em solicitude, em cuidado, ou seja, "possibilitá-la a assumir seus próprios caminhos, crescer, amadurecer, encontrar-se consigo mesmo" (14).

A compreensão do ser-pessoa-com-dor permite ao profissional perceber que só o Ser-aí particular decide a sua existência e pode fazê-lo assumindo-a ou negligenciando-a. O ser-pessoa-com-dor deve tornarse consciente de si enquanto-ser-no-mundo de contradições factuais que ele mesmo não escolheu.

É importante que o profissional de saúde entenda que ele precisa compartilhar, ainda que por momentos, do mundo pessoal da pessoa-com-dor, o mundo de sua auto realização, para, só então, ter condições de compreendê-la nesse mundo. Para a concretização desse esforço, necessita ser preparado no que tange à dimensão humanista e com o olhar voltado para o ser existindo no mundo, enfocando a dor enquanto uma facticidade que não diminui a integridade do ser humano, que continua a ter o direito de viver com dignidade.

Há de se buscar na enfermagem os novos caminhos que estão aí abertos e que possibilitam novos horizontes. Faz-se necessário explicitar qual o papel do enfermeiro na vida cotidiana da pessoa com dor, pois é pela percepção que se revela simultaneamente o sentido da existência do sujeito em seu mundo-vida. A compreensão do que efetivamente está sendo expresso e comunicado, quer pela linguagem verbal, escrita ou silenciosa, ou pelas expressões corporais, pela relação com o mundo vivido, é imprescindível para o conhecimento das situações existenciais.

Acredito que o compromisso da enfermagem para amenizar os desconfortos vai além das intervenções biológicas. O enfoque também deve estar voltado para aspectos existenciais onde haja espaço para a expressão dos sentimentos, de forma que as subjetividades sejam afloradas. Para isso, é necessário ouvir a pessoa em situação de dor e buscar alternativas que amenizem seu sofrimento, que melhorem sua qualidade de vida.
Enquanto enfermeira-pesquisadora que se interessa pelo cuidado da pessoa-com-dor, acredito ser importante levar estes dados aqui apreendidos ao conhecimento dos profissionais que atuam na Clínica para o Tratamento da Dor, como uma proposta, a princípio, de reflexão. A tarefa da reflexão é tentar colocar de modo claro as estruturas da existência ser-pessoa-com-dor - assim como captar a sua significação, para, então, como diria Heidegger, "abrir horizontes". E necessário conscientização dos profissionais de saúde e autoridades para a formação equipes multi e interdisciplinares.

\section{REFERÊNCIAS BIBLIOGRÁFICAS}

(1) Feuerstein M. Definition of pain. In: Tollison CD. Handbook of chronic pain management, Baltimore: Willians \& Wilkins, 1989. p.2-5.

(2) Azambuja NAVC, Silva MARA, Reveilleau AC. Dor crônica. Acta Médica, 1983; p.343-60.

(3) Pimenta CAM, Teixeira MJ. Avaliação da dor. Rev Med 1997; 76:27-35.

(4) Melsack R. The McGill pain questionnaire: major properties and scorin methods. Pain 1975; 1:277-99.

(5) Capalbo C. Fenomenologia e ciências humanas. $3^{\mathrm{a}}$ ed. Londrina: UEL; 1996.

(6) Martins J, Boemer MR, Ferraz CA. A fenomenologia como alternativa metodológica para pesquisa: algumas considerações. Rev Esc Enferm USP 1990; 24(1):139-47.

(7) Heidegger M. Ser e tempo (Parte I). Trad. de Márcia de Sá Cavalcanti. 2a ed. Petropolis: Vozes; 1986.

(8) May R, Angel E, Ellenberger HF. Existencia-nueva dimensión en psiquiatria y psicologia. Madri: Gredos; 1977.

(9) Pimenta CAM. Atitudes de doentes com dor crônica frente a dor. [Livre-Docência]. São Paulo(SP): Escola de Enfermagem, Universidade de São Paulo; 1999.

(10) Suzuki SO, Tavares R. Brasil desconhece custo real. Folha de São Paulo 2002 fey 22; Trainee Especial; 2.

(11) Turk DC. Biopsychosocial perspective on chronic pain.In: Gatchel RL, Turk DC. Psychological approaches to pain management: a practitioner's handbook. New York, Guilford, 1996. cap.1, p.3-32.

(12) Merskey H. Pain and psycological medicine. In: Wall P, Melzack R. Textbook of pain. 3.ed. Edinburgh; Churchill Livingstone, 1994. cap.47, p.903-20.

(13) Forghieri YC. Fenomenologia e psicologia. Silo Paulo: Cortez/Autores Associados, 1984..

(14) Spanoudis S. A todos que procuram o próprio caminho [Apresentação e Introdução]. In: Heidegger M. Todos nós...ninguém - um enfoque fenomenológico do social. Trad. de Dulce Maria Critelli. São Paulo: Moraes; 1981.

\section{Artigo recebido em 01/04/02 Artigo aprovado em 07/02/03}

